\title{
SUPERCRITICAL CARBON DIOXIDE EXTRACTION OF CITRONELLA OIL FROM CYMBOPOGON WINTERIANUS USING TAGUCHI ORTHOGONAL ARRAY DESIGN
}

\author{
RINALDI SALEA, STEVANUS HIENDRAWAN, ERNA SUBROTO, BAMBANG VERIANSYAH, RAYMOND R. \\ TJANDRAWINATA*
}

\author{
Dexa Laboratories of Biomolecular Sciences (DLBS), Industri Selatan V Block PP No. 7, Jababeka Industrial Estate II, Cikarang 17550, West \\ Java, Indonesia \\ Email: raymond@dexa-medica.com \\ Received: 01 Aug 2018, Revised and Accepted: 04 Sep 2018
}

ABSTRACT

Objective: Optimum condition for the extraction of citronella oil from citronella (Cymbopogon winterianus) using supercritical carbon dioxide (SC$\mathrm{CO}_{2}$ ) was investigated.

Methods: In order to determine the optimum extraction condition, a Taguchi experiment with L9 orthogonal array design was used. Effects of pressure, temperature and dynamic extraction time on citronella oil yield were investigated at levels ranging between $10-15 \mathrm{MPa}, 35-45^{\circ} \mathrm{C}$ and 60 180 min, respectively.

Results: The highest citronella oil yield (3.206\%) was achieved at a factor combination of $15 \mathrm{MPa}, 50{ }^{\circ} \mathrm{C}$ and $180 \mathrm{~min}$. The obtained citronella oil yield from SC-CO $\mathrm{CO}_{2}$ extraction was higher than that of percolation as the solvent extraction method using ethanol, which gave a citronella oil yield of $1.4 \%$. The experimental oil yield at optimum condition was in accordance to the values predicted by a computational process using Taguchi method. Analysis of variance (ANOVA) with 95\% confidence interval indicates that extraction temperature is the most significant factor in maximizing citronella oil yield, followed by dynamic extraction time and pressure.

Conclusion: Optimization process for oil yield from $\mathrm{SC}_{-} \mathrm{CO}_{2}$ extraction of citronella (Cymbopogon winterianus) was successfully performed using Taguchi $\mathrm{L}_{9}$ orthogonal array design. This study demonstrates that Taguchi method was able to simplify the experimental procedure of $\mathrm{SC}^{-\mathrm{CO}_{2}}$ process.

Keywords: Supercritical carbon dioxide extraction, Citronella, Cymbopogon winterianus, Optimization, Taguchi

(C) 2018 The Authors. Published by Innovare Academic Sciences Pvt Ltd. This is an open-access article under the CC BY license (http://creativecommons.org/licenses/by/4.0/] DOI: http://dx.doi.org/10.22159/ijap.2018v10i6.28880

\section{INTRODUCTION}

Citronella is a plant originated from India and Sri Lanka which belongs to the genus Cymbopogon. This plant is commonly found growing wild in most tropical Asian, American and African countries [1]. Oil of citronella is one of the most important essential oils obtained from different species of aromatic grasses. This oil is mainly used as a source of important perfumery chemicals due to its citronellal and geraniol contents, which are extensively used in soap, perfumery, cosmetic and flavouring industries throughout the world. Citronella oil can be used effectively as a plant-based insect repellent. The oil has also been known to possess antimicrobial, anthelmintic, antiparasitic, anti-inflammatory, anticonvulsant, antispasmodic and antioxidant properties [2].

Pharmacologically-active compounds in plants are usually present in low concentrations. Previously, various different extraction methods have been developed for the effective and selective extractions of these compounds from raw materials. Our laboratories have developed and investigated various extraction techniques and biological assays on natural products [3-7]. Current methods that are commonly used for the extraction of citronella are hydrodistillation, steam distillation and solvent extraction [8-9]. However, hydro- and steam distillation have several drawbacks, such as high-temperature operation which leads to the breakdown of thermolabile components and the hydration of chemical constituents, while the major disadvantage of solvent extraction is the presence of solvent residue in the product.

Extraction of essential oil-bearing plants with supercritical carbon dioxide $\left(\mathrm{SC}-\mathrm{CO}_{2}\right)$ extraction is still considered as a new process on an industrial scale. Several studies have been done in recent years on the applications of $\mathrm{SC}-\mathrm{CO}_{2}$ on various essential oil-bearing plants such as black cumin, clove, cinnamon and ginger [10-13]. Carbon dioxide $\left(\mathrm{CO}_{2}\right)$ behaves as a lipophilic solvent. Thus, it is able to extract most non-polar solutes in plant and animal materials, including antioxidants, pigments, flavors, fragrances, fatty acids, and essential oils. Separation of $\mathrm{CO}_{2}$ from the extract is simple and nearly instantaneous, leaving no solvent residue in the extract, as would be typical with organic solvent extraction. Unlike liquid solvents, the solving power of $\mathrm{SC}-\mathrm{CO}_{2}$ can be easily adjusted by slight changes in the temperature and pressure, making it possible to extract particular compounds of interest. In addition, $\mathrm{CO}_{2}$ is inexpensive, available in high purity, FDA-approved and classified as a generally recognized as safe (GRAS) compound. $\mathrm{CO}_{2}$ is also a good solvent for thermolabile compounds that are sensitive to high temperature because $\mathrm{CO}_{2}$ has a relatively low critical point, with a critical temperature (Tc) and critical pressure (Pc) of $31^{\circ} \mathrm{C}$ and $7.38 \mathrm{MPa}$, respectively [14].

Taguchi method has widely been used in many engineering applications since it is a powerful tool to design and investigate the parameters [15-16]. It is a technique among statistical experimental design methods that comprises a special design of an orthogonal array $(\mathrm{OA})$ to study the entire parameter with a small number of experiments. Thus, by this method, it is possible to reduce both of the time and cost needed for experimental investigations and improve its performance characteristics [17]. The objective of this present study was to investigate the optimum condition for citronella oil extraction through SC- $\mathrm{CO}_{2}$ extraction and to investigate the effect of extraction pressure and temperature and dynamic extraction time on citronella oil yield using Taguchi method. In addition, the yield and chemical profile of citronella oil extracts obtained by $\mathrm{SC}-\mathrm{CO}_{2}$ extraction were also evaluated and compared to those obtained by the solvent extraction method using ethanol.

\section{MATERIALS AND METHODS}

\section{Materials}

The fresh stalks and leaves of citronella (Cymbopogon winterianus) were obtained from CV Pavettia Kurnia Atsiri (Subang, Indonesia). 
Food-grade liquid $\mathrm{CO}_{2}$ (purity of 99.99\%) was supplied in cylinder tube by PT Inter Gas Mandiri (Cikarang, Indonesia). Ethanol $96 \%$ (technical grade) was purchased from PT Brataco Chemika (Cikarang, Indonesia). Analytical standard of citral and geraniol were purchased from Sigma-Aldrich,Co.(MO, USA).

\section{Material preparation}

Citronella was air-dried at room temperature for $1 \mathrm{w}$. Prior to the extraction process, dried citronella was manually chopped $( \pm 1 \mathrm{~cm})$ and milled with a conical mill (Quadro Comil, Canada) with 040G screen and square impeller at $5000 \mathrm{rpm}$. These ground samples were packaged in a polyethylene bag and stored in a refrigerator. Moisture content of the sample before extraction was $14 \%$ wet basis (w. b).

\section{Supercritical carbon dioxide (SC- $\mathrm{CO}_{2}$ ) extraction}

$\mathrm{SC}-\mathrm{CO}_{2}$ extraction was performed using a customized supercritical fluid apparatus described in the previous study [10]. SC- $\mathrm{CO}_{2}$ extraction was carried out using a supercritical fluid extractor with $\mathrm{CO}_{2}$ cycle system (KIST-Korea). A $1000 \mathrm{ml}$ stainless steel extraction column loaded with approximately $50 \mathrm{~g}$ of dried and milled citronella was connected to the system. $\mathrm{CO}_{2}$ pump (HKS-12000, South Korea) was cooled using circulating chiller (Lab. Companion, USA) and the pressurized $\mathrm{CO}_{2}$ was delivered to the extraction vessel through a preheater. Temperatures of extraction column and preheater were controlled by a circulating heater (Lab. Companion, USA). The outlet of extraction column was connected to a back pressure regulator (Tescom, USA) to control the pressure in the extraction vessel. Extraction experiments were commenced when the system has reached the predetermined pressure and temperature. There were two stages of extraction which consisted of static and dynamic stages. The static stage was $60 \mathrm{~min}$ for all experiments, and the dynamic stage was varied. $\mathrm{CO}_{2}$ flow rate was kept at $20 \mathrm{ml} / \mathrm{min}$, measured at operating pressure and temperature for all experiments. SC- $\mathrm{CO}_{2}$ was expanded across the separator vessel, and the extracts were collected in a glass vial after the experiment has been finished.

\section{Solvent extraction (percolation)}

Approximately $100 \mathrm{~g}$ of dried and grounded citronella were loaded into a $2500 \mathrm{ml}$ custom-built percolator. Ethanol (96\% v/v) with a total volume of $2600 \mathrm{ml}$ was used as the solvent. A HKS-12000 Pump (Korea) was used to continuously deliver solvent through the system at a rate of $180 \mathrm{ml} / \mathrm{min}$. After $6 \mathrm{~h}$ of extraction time, the solvent was then removed by evaporation process at a reduced pressure using Rotavapor R-215 (Buchi, Switzerland). The amount of remaining extract was determined as the yield of the experiment.

\section{Gas chromatography (GC) analysis}

Gas chromatography (GC) analysis was performed with a PerkinElmer GC Clarus 680 equipped with a flame ionization detector (FID) and an Elite-5 (5\% phenyl, 95\% dimethylsiloxane) capillary column $(30 \mathrm{~m} \times 0.25 \mathrm{~mm}$ i.d $\times 0.25 \mu \mathrm{m}$ film thickness $)$. Nitrogen was used as the carrier gas at a flow rate of $0.7 \mathrm{ml} / \mathrm{min} .1$ $\mu \mathrm{l}$ of sample was injected using the split mode (split ratio of $1: 10$ ). Injector and detector temperatures were $150^{\circ} \mathrm{C}$ and $320^{\circ} \mathrm{C}$, respectively. Oven temperature was set at $80^{\circ} \mathrm{C}$, programmed to $120^{\circ} \mathrm{C}$ at a rate of $3^{\circ} \mathrm{C} / \mathrm{min}$ and further programmed at a rate of $20^{\circ} \mathrm{C} / \mathrm{min}$ to $310^{\circ} \mathrm{C}$.

\section{Taguchi orthogonal array}

Taguchi method has widely been used in many engineering applications since it is a powerful tool to design and investigate the parameters. It is a technique among statistical experimental design methods that comprises a special design of an orthogonal array (OA) to study the entire parameters with a small number of experiments. Thus, by this method, it is possible to reduce both of the time and cost needed for experimental investigations and to improve the performance characteristics [18]. A Taguchi $\mathrm{L}_{9}$ orthogonal array design was used to investigate the optimum condition in $\mathrm{SC}^{-\mathrm{CO}_{2}}$ extraction process since it is the most suitable method for the investigated condition, i.e., three factors with three levels (values). The factors and levels are listed in table 1 , whereas the structure of Taguchi $L_{9}$ orthogonal array design is shown in table 2.

The data obtained from $\mathrm{SC}-\mathrm{CO}_{2}$ extraction process was subjected to signal-to-noise $(\mathrm{S} / \mathrm{N})$ ratio calculation. $\mathrm{S} / \mathrm{N}$ ratio calculation is an evaluation of output performance stability which measures the level of performance and effect of noise parameters on performance. The experimental results should be transformed into $\mathrm{S} / \mathrm{N}$ ratios, which mainly consist of three types, including smaller-the-better, nominalthe-best and larger-the-better. In this study, target values of 'larger is better' was used since the purpose of this study was to obtain the highest yield of citronella oil. The larger difference value $(\Delta)$ in the parameters indicates that the parameters will affect the process since any change in signal will cause a larger effect on the output factors being measured. $\mathrm{S} / \mathrm{N}$ ratio is calculated using the following equation:

$$
\frac{S}{N}=-10 \log \left(\frac{1}{n} \sum_{i=1}^{n} \frac{1}{y_{i}^{2}}\right)
$$

where $y_{i}$ represents the experimentally observed value of the $i^{\text {th }}$ experiment, and $\mathrm{n}$ is the number of the trial at the same level. Statistical analysis was performed using MINITAB v.15 (Minitab Inc., USA) statistical software package.

Table 1: Factors and levels used in experimental design

\begin{tabular}{llll}
\hline Level & Factors & & \\
\cline { 2 - 4 } & Pressure (MPa) & Temperature $\left({ }^{\circ} \mathbf{C}\right)$ & Dynamic time (min) \\
\cline { 2 - 4 } & A & B & C \\
\hline 1 & 10 & 40 & 60 \\
2 & 12.5 & 45 & 120 \\
3 & 15 & 50 & 180 \\
\hline
\end{tabular}

Table 2: Standard for $L_{9}$ orthogonal arrays

\begin{tabular}{llll}
\hline Run & Independent variables & & C \\
\cline { 2 - 4 } & A & B & 1 \\
\hline 1 & 1 & 1 & 2 \\
2 & 1 & 2 & 3 \\
3 & 1 & 3 & 2 \\
4 & 2 & 1 & 3 \\
5 & 2 & 2 & 1 \\
6 & 2 & 3 & 3 \\
7 & 3 & 1 & 1 \\
8 & 3 & 2 & 2 \\
9
\end{tabular}




\section{RESULTS AND DISCUSSION}

\section{Effect of SC- $\mathrm{CO}_{2}$ extraction conditions on citronella oil yield}

Based on experimental designs in the framework of Taguchi method and according to the array and orthogonal $\mathrm{L}$, and considering the change of condition and different parameters which consisted as pressure $(\mathrm{P})$, temperature (T) and dynamic extraction time $(\mathrm{t}), 9$ experiments were performed in the present study. Summary of SC- $\mathrm{CO}_{2}$ experiments using Taguchi method is shown in table 3. Experiment results showed that the obtained citronella oil yield was varied from $0.854-2.802 \%$.

Table 3: Results of citronella oil using $\mathrm{SC}^{-\mathrm{CO}_{2}}$ extraction

\begin{tabular}{lllll}
\hline Run & Pressure (MPa) & Temperature $\left(^{\circ} \mathbf{C}\right)$ & Dynamic time (min) & Yield (\%) \\
\hline 1 & 10 & 40 & 60 & 0.854 \\
2 & 10 & 45 & 120 & 1.972 \\
3 & 10 & 50 & 180 & 2.132 \\
4 & 12.5 & 40 & 120 & 1.324 \\
5 & 12.5 & 45 & 180 & 2.174 \\
6 & 12.5 & 50 & 60 & 2.802 \\
7 & 15 & 40 & 180 & 2.454 \\
8 & 15 & 45 & 60 & 1.528 \\
9 & 15 & 50 & 120 & 2.448 \\
\hline
\end{tabular}

Fig. 1 shows the main effect plot of citronella oil yield to different extraction factors and levels. Main effect plot was performed based on the average response for each combination of control factor levels. It can be seen in fig. 1 that an increased pressure from 10 to $12.5 \mathrm{MPa}$ resulted in a significant increment of citronella oil yield, while further increasing pressure from 12.5 to $15 \mathrm{MPa}$ resulted in a smaller citronella oil yield increment. Generally, using a higher pressure at isothermal conditions resulted in an increased solvent density and subsequently solvent power and solubility of the compounds. As the density increased, the distance between molecules was decreased, and interactions between compounds and $\mathrm{CO}_{2}$ were increased, which led to greater solubility of compounds in $\mathrm{CO}_{2}[19]$.
The effect of temperature on the yield of citronella oil obtained in this study presents analogies to the influence of temperature on the solubility of solid materials in supercritical fluids. Solubility of solids in supercritical fluids is the combination of two competing effects, which consists of the increased solid volatility and the decreased solvent density along with temperature rise [19-20].

Extraction time exhibited a positive impact on citronella oil yield as shown in fig. 1. The citronella oil yield was increased along with increased dynamic extraction time. The results showed that increased dynamic extraction time to $180 \mathrm{~min}$ was able to enhance the yield of citronella oil.
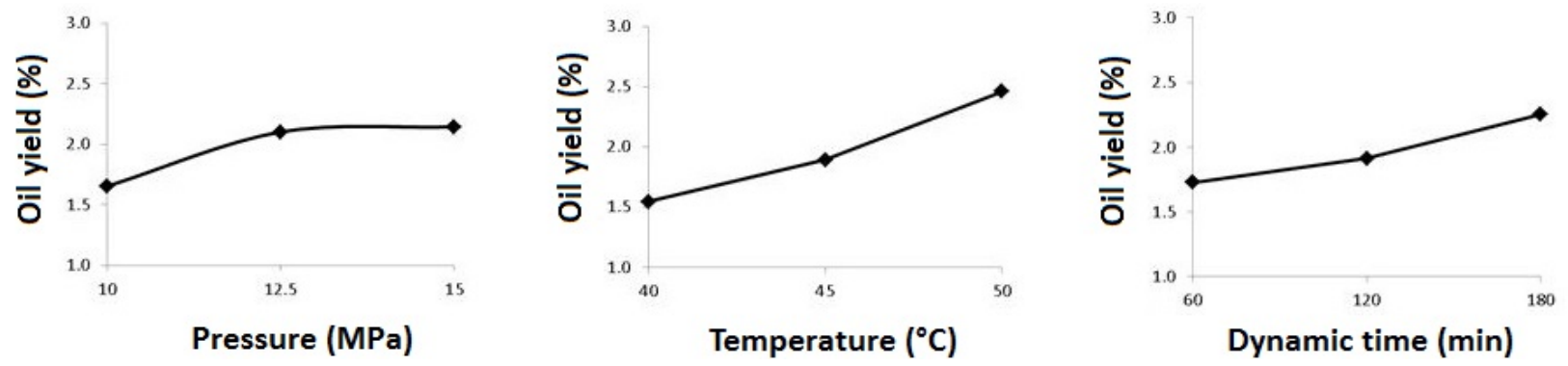

Fig. 1: Main effects plot of taguchi method for citronella oil yield

\section{Optimum condition}

The main effect plots of $\mathrm{S} / \mathrm{N}$ ratios clearly depicted the optimum level of each significant factor on extraction yield as shown in fig. 1 . In this study, since the target value was 'larger is better', the optimum condition for each factor was defined as the level that gives the highest point of means of each plot for citronella oil yield. Based on the results of Taguchi method, the highest citronella oil yield from SC- $\mathrm{CO}_{2}$ extraction was obtained at a pressure of $15 \mathrm{MPa}$, the temperature of $50{ }^{\circ} \mathrm{C}$ and dynamic extraction time of $180 \mathrm{~min} . \mathrm{S} / \mathrm{N}$ ratio calculation results are shown in table 4 . Greater difference value $(\Delta)$ of the average $S / N$ ratio indicated that the control factors have a greater substantial effect on $\mathrm{S} / \mathrm{N}$ ratio. Based on the $\mathrm{S} / \mathrm{N}$ ratio calculation, the most influencing parameters in this process is extraction temperature, followed by dynamic extraction time and extraction pressure. Thereby, the influencing parameters in the extraction process follow the order: extraction temperature> dynamic extraction time $>$ extraction pressure.

Analysis of variance (ANOVA) was carried out to evaluate the significance of extraction pressure, extraction temperature and dynamic extraction time on the yield of citronella oil using $\mathrm{SC}_{-} \mathrm{CO}_{2}$ extraction, as shown in table 5. Results showed that different level of parameters exhibited no significant effect on citronella oil yield $(p>0.05)$. However, it was found that temperature has a greater effect than dynamic extraction time and pressure on citronella oil yield. This result was in a good agreement to the $\mathrm{S} / \mathrm{N}$ ratio calculation results.

Table 4: S/N value calculated for each parameter and level

\begin{tabular}{llll}
\hline Level & Pressure (MPa) & Temperature $\left({ }^{\circ} \mathbf{C}\right)$ & Dynamic time (min) \\
\hline 1 & 2.103 & 1.533 & 1.923 \\
2 & 5.184 & 5.243 & 4.795 \\
3 & 5.956 & 7.660 & 7.007 \\
$\Delta$ (max-min) & 3.853 & 6.126 & 5.084 \\
Rank & 3 & 1 & 2 \\
\hline
\end{tabular}


Table 5: Analysis of variance (ANOVA) of citronella oil yield

\begin{tabular}{llllll}
\hline Source & DF & Seq SS & Adj SS & Adj MS & F-value \\
\hline Pressure & 2 & 13.02 & 13.02 & 6.508 & 0.62 \\
Temperature & 2 & 34.75 & 34.75 & 17.375 & 1.65 \\
Dynamic time & 2 & 16.20 & 16.20 & 8.098 & 0.77 \\
Residual Error & 2 & 21.04 & 21.04 & 10.519 & 0.377 \\
Total & 8 & 85 & & & 0.565 \\
\hline
\end{tabular}

DF: Degree of freedom; Seq SS: Sequentials sums of squares; Adj SS: Adjusted sums of squares; Adj MS: Adjusted means of squares

\section{Experimental validation}

Experimental validation is the final step in the modeling process to investigate the accuracy and robustness of the established model. The final analysis involved a comparison between the predicted values of the established model and experimentally validated values. The predicted value at optimized condition is $2.93 \%$, while the actual value at this condition is $3.206 \%$. Percentage error found in this study was $9.1 \%$. It was found that the average of percentage error was less than $15 \%$, confirming and concluding that the methodology used in establishing the model in this scientific research was systematic. Citronella oil yield obtained in this study was higher than previous studies using $\mathrm{SC}_{-}-\mathrm{CO}_{2}$. In previous study, Silva et al. used SC- $-\mathrm{CO}_{2}$ to extract citronella essential oil. They varied the extraction temperature from 40 to $80^{\circ} \mathrm{C}$, as well as the pressure from 6.2 to $18 \mathrm{MPa}$. The results showed that the best citronella extraction yield was $2.18 \%$ at $60^{\circ} \mathrm{C}$ and $15 \mathrm{MPa}$ for $60 \mathrm{~min}$ [21].

\section{Comparison with ethanol extraction (percolation)}

In comparison to the solvent extraction method, the optimum yield from $\mathrm{SC}-\mathrm{CO}_{2}$ extraction was much higher than percolation (table 6). Moreover, in terms of dynamic extraction time, $\mathrm{SC}-\mathrm{CO}_{2}$ extraction was less time-consuming than conventional methods, and this extraction method does not need a further process to separate the remaining organic solvent in the obtained extract. Therefore, $\mathrm{SC}-\mathrm{CO}_{2}$ extraction exhibited a potential to be a better alternative for citronella oil extraction, since it offers the use of non-toxic, nonexplosive, environmentally-friendly, cost-effective, time-saving and selectively-adjustable solvent in the extraction process.

Table 6: Citronella oil yields obtained by ethanol extraction and $\mathrm{SC}-\mathrm{CO}_{2}$ extraction at optimum condition

\begin{tabular}{llll}
\hline Methods & Yield (\%) & Citral (\%) & Geraniol (\%) \\
\hline $\mathrm{SC}-\mathrm{CO}_{2}$ extraction & 3.206 & 0.508 & 3.620 \\
Ethanol extraction & 1.400 & 0.069 & 0.473 \\
\hline
\end{tabular}

\section{CONCLUSION}

Process optimization of SC- $\mathrm{CO}_{2}$ extraction on the yield of citronella (Cymbopogon winterianus) oil was successfully performed using Taguchi L 9 orthogonal array design. Optimum condition to obtain the highest oil yield (3.206\%) was achieved at extraction pressure of 15 $\mathrm{MPa}$, extraction temperature of $50^{\circ} \mathrm{C}$ and dynamic extraction time of $180 \mathrm{~min}$. The experimental oil yield at optimum condition was in a good agreement with the predicted computational results. $\mathrm{S} / \mathrm{N}$ ratio calculation and ANOVA identified extraction temperature as the main factor that exhibited the most influential effect on SC- $\mathrm{CO}_{2}$ extraction of citronella. Compared to the conventional method in this study (percolation using ethanol extraction), $\mathrm{SC}-\mathrm{CO}_{2}$ extraction process resulted in a higher yield of citronella oil with a shorter period of extraction time.

\section{ACKNOWLEDGMENT}

The authors acknowledge Dexa Laboratories of Biomolecular Sciences (DLBS)-PT. Dexa Medica for financial support. The authors would like to thank Isabela Anjani for a critical review on this manuscript.

\section{AUTHORS CONTRIBUTIONS}

All the author have contributed equally

\section{CONFLICT OF INTERESTS}

The authors declared no conflicts of interest with respect to the authorship and/or publication.

\section{REFERENCES}

1. Man HC, Hamzah MZ, Jamaludin H, Abidin ZZ. Preliminary study: kinetics of oil extraction by ohmic heated hydrodistillation. APCBEE Procedia 2012;3:124-8.

2. Kakaraparthia PS, Srinivasa KVNS, Kumara JK, Kumara AN, Rajputa DK, Sarma VUM. Variation in the essential oil content and composition of Citronella (Cymbopogon winterianus Jowitt.) in relation to the time of harvest and weather conditions. Ind Crops Prod 2014;61:240-8.
3. Tandrasasmita OM, Lee JS, Baek SH, Tjandrawinata RR. Induction of cellular apoptosis in human breast cancer by DLBS1425, a Phaleria macrocarpa compound extract, via downregulation of PI3-kinase/AKT pathway. Cancer Biol Ther 2010;10:814-23.

4. Tandrasasmita OM, Wulan DD, Nailufar F, Sinambela J, Tjandrawinata RR. Glucose-lowering effect of DLBS3233 is mediated through phosphorylation of tyrosine and upregulation of PPAR $\gamma$ and GLUT4 expression. Int J Gen Med 2011;4:345-57.

5. Tjandrawinata RR, Nofiarny D, Susanto LW, Hendri P, Clarissa A. Symptomatic treatment of premenstrual syndrome and/or primary dysmenorrhea with DLBS1442, a bioactive extract of Phaleria macrocarpa. Int J Gen Med 2011;4:465-76.

6. Salea R, Widjojokusumo E, Veriansyah B, Tjandrawinata RR. Optimizing oil and xanthorrhizol extraction from Curcuma xanthorrhiza Roxb. rhizome by supercritical carbon dioxide. J Food Sci Technol 2014;51:2197-203.

7. Karsono AH, Tandrasasmita OM, Tjandrawinata RR. Molecular effects of bioactive fraction of Curcuma mangga (DLBS4847) as a down-regulator of $5 \alpha$-reductase activity pathways in prostatic epithelial cells. Cancer Manag Res 2014;6:267-78.

8. Wany A, Kumar A, Nallapeta S, Jha S, Nigam VK, Pandey SM. Extraction and characterization of essential oil components based on geraniol and citronellol from Java citronella (Cymbopogon winterianus Jowitt). Plant Growth Regul 2014;73:133-45.

9. Timung R, Barik CR, Purohit S, Goud VV. Composition and antibacterial activity analysis of citronella oil obtained by hydrodistillation: process optimization study. Ind Crops Prod 2016;94:178-88.

10. Salea R, Widjojokusumo E, Hartanti AW, Veriansyah B, Tjandrawinata RR. Supercritical fluid carbon dioxide extraction of Nigella sativa (black cumin) seeds using Taguchi method and full factorial design. Biochem Compd 2013. Doi:10.7243/20529341-1-1.

11. Chatterjee D, Bhattacharjee P. Supercritical carbon dioxide extraction of eugenol from clove buds. Food Bioprocess Technol 2013;6:2587-99. 
12. Singh A, Ahmad A. Optimization of total essential oil yield of Cinnamomum zeylanicum N. by using supercritical carbon dioxide extraction. Int J Sci Eng Res 2015;6:318-27.

13. Salea R, Veriansyah B, Tjandrawinata RR. Optimization and scale-up process for supercritical fluids extraction of ginger oil from Zingiber officinale var. Amarum. J Supercrit Flu 2017;120:285-94.

14. McHugh M, Krukonis V. Supercritical fluid extraction: principles and practice. 2nd ed. United Kingdom: ButterworthHeinemann; 1994.

15. Ansari K, Goodarznia I. Optimization of supercritical carbon dioxide extraction of essential oil from spearmint (Menthaspicata L.) leaves by using Taguchi methodology. J Supercrit Flu 2012;67:123-30.

16. Subroto E, Widjojokusumo E, Veriansyah B, Tjandrawinata RR. Supercritical $\mathrm{CO}_{2}$ extraction of candlenut oil: process optimization using taguchi orthogonal array and physicochemical properties of the oil. J Food Sci Technol 2017;54:1286-92.

17. Chuichulcherm S, Prommakort S, Srinophakun P Thanapimmetha A. Optimization of capsaicin purification from Capsicum frutescens Linn. with column chromatography using Taguchi design. Ind Crops Prod 2013;44:473-9.

18. Montgomery DC. Design and analysis of experiments. 6th ed. Washington DC. John Wiley and Sons Inc; 2005.

19. Reverchon E, Marco ID. Review: supercritical fluid extraction and fractionation of natural matter. I Supercrit Fluids 2006;38:146-66.

20. Danh LT, Mammucari R, Truong P, Foster N. Response surface method applied to supercritical carbon dioxide extraction of Vetiveria zizanioides essential oil. Chem Eng J 2009;155:617-26.

21. Silva CF, Moura FC, Mendes MF, Pessoa FLP. Extraction of citronella (Cymbopogon nardus) essential oil using supercritical C02: experimental data and mathematical modeling. Braz J Chem Eng 2011;28:343-50. 